\title{
Ethical Leadership, Affective Organizational Behaviour and Leader-Member Exchange as Predictors for Employees Performance
}

\author{
${ }^{1}$ Mohammed S. Alkathiri, ${ }^{1}$ Abuelhassan E. Abuelhassan, ${ }^{2}$ Gamal S.A. Khalifa, \\ ${ }^{1}$ Mohammed Nusari and ${ }^{1}$ Ali Ameen \\ ${ }^{1}$ Faculty of Business and Accountancy, \\ ${ }^{2}$ Faculty of Hospitality and Tourism, Lincoln University College (LUC), Selangor, Malaysia \\ (GSK00@fayoum.edu.eg)
}

\begin{abstract}
Drawing on leadership theory and social exchange theory, the study investigated the role of Ethical Leadership (EL), Leader-Member Exchange (LMX) and Affective Organizational behavior (AOC) Employee Performance (PERF) in the Abu Dhabi police. The current study adopted SEM to test the study's hypothesis. A sample of 558 employees in the Abu Dhabi police was selected randomly. In this representative sample, a survey was carried out to find out the extent of EL, AOC and LMX influence on PERF. All the study's hypothesis were supported. EL, AOC and LMX significantly predicting employee performance. The proposed model explained $63.9 \%$ of the variance in employee performance. Finally, theoretical and managerial implications were discussed.
\end{abstract}

Key words: Ethical leadership, employee performance, affective organizational behavior, leader-member exchange, UAE, social exchange

\section{INTRODUCTION}

Recently and based on the increased competition between service providers, along with large development in the service economy has constrained associations to focus greater attention on the nature and quality of services provided to customers (Hussein et al., 2013; Khalifa and Hewedi, 2016; Abou-Shouk and Khalifa, 2017; Khalifa and Ali, 2017; Mohamud et al., 2017). Service quality is mostly related to employee performance (Khalefa, 2015; Khalifa and Fawzy, 2017). Researchers have argued that continuous change requires employees to modify not only work routines but also social practices (e.g., relations with their managers and peers). To adapt to the day by day challenge of real-time adaptation, workers specifically hold powerful elements of their performance routines and integrate them with new, more proficient ones (Carter et al., 2013). Accordingly, these employees regularly encounter challenges and tensions in keeping up prior levels of performance while adjusting to their new job requirements. In order to mitigate the tensions and facilitate effective performance, managers must show suitable leadership behaviors (Mohamed et al., 2018).

In the present evolving conditions, if organizations target to have a sustainable progress, strategic superiority and corporate image at that point they need to set up a culture that supports and supports the ethical behaviors (Abd-Elaziz et al., 2015; Badran and Khalifa, 2016; Hoch et al., 2018; Nusari et al., 2018; Reb et al., 2018). While, building up the ethical working condition as a good example, leader's behaviors impact the other behaviors in the associations and their behaviors turn into the most critical factor in this process. In this context, ethical leadership can be defined as "the demonstration of normatively appropriate conduct through personal actions and interpersonal relationships (Walumbwa et al., 2011; Khalifa and Abou-Shouk, 2014; Demirtas and Akdogan, 2015; Qoura and Khalifa, 2016; Mohamed et al., 2018).

Several theories and models have been developed and proposed in order to predict and explain leadership behaviour with employees. Leader-Member Exchange (LMX) theory indicates that leaders develop distinctive quality relationships with different subordinates through social exchanges (Graen and Scandura, 1987; Graen and Uhl-Bien, 1995; Kim et al., 2008; Dulebohn et al., 2012; Park et al., 2015; Buch et al., 2016; Epitropaki et al., 2016; Liao et al., 2017; Reb et al., 2018; Shamsi et al., 2018; Hoch et al., 2018; Hsiung and Bolino, 2018). However, LMX theory also has long documented the role of equity in the development of LMX (e.g., Bauer and

Corresponding Author: Gamal S.A. Khalifa, Faculty of Tourism and Hotels, Fayoum University, Fayoum, 
Green, 1996; Dienesch and Liden, 1986; Graen and Scandura, 1987). Justice perceptions in organizations are defined as employee's perceptions about how fairly they are treated by their direct supervisors and/or their organization (Greenberg, 1996). Organizational justice provides a valuable perspective for understanding how subordinate's LMX perceptions develop in terms of "fair treatment" and "fair exchange" issues (Pillai et al., 1999; Scandura, 1999). Indeed, the main premise of LMX theory that there are differentiated groups (i.e., in groups and out-groups) based on the quality of LMX relationships is inconsistent with "norms of equality" (Scandura, 1999). As such because justice is socially constructed (Colquitt et al., 2001) and social exchange theory provides the basis for LMX theory (Dienesch and Liden, 1986; Eisenberg, 2014; Eisenberger et al., 2014), a subordinate's justice perceptions play an important role for understanding how that individual's LMX perceptions develop (Erdogan et al., 2006; Erdogan and Enders, 2007; Ayers, 2015; Lozano et al., 2015; Reb et al., 2018). This study attempts to achieve the following research objectives: to examine the effect of in ethical leadership on employee performance. To examine the effect of LMX on employee performance. To examine the effect of $\mathrm{AOC}$ on employee performance.

\section{Theoretical framework and hypothesis formulation Ethical leadership and employee performance:} Likewise, moral leaders, those who demonstrate integrity and are concerned with the collective good rather than self-interest are highly respected, admired and viewed as ideal leaders by Chinese employees (Niu et al., 2009; Chen et al., 2014; Tang et al., 2015). These leaders are likely to serve as role models for employees and exert referent power on them which are important ingredients for forming a more personalized emotional bond between the leader and the follower (Chen et al., 2014). As a result, both benevolence and morality will likely motivate followers to engage in social exchanges by putting more effort into work and going above and beyond for their leaders (Colquitt et al., 2007; Loi et al., 2009; Ullah et al., 2017).

The community's increased attention to morally acceptable business practices by managers has led to an emerging interest in ethical leadership (Bouckenooghe et al., 2015; Fiaz et al., 2017). Although, ethical leadership has had considerable intuitive support, only recently has this leadership approach received strong theoretical support in the management literature (e.g., Demirtas and Akdogan, 2015; Shin et al., 2015; Shapiro and Stefkovich, 2016; Liao et al., 2017; Walumbwa et al., 2017; Belschak et al., 2018; Byun et al.,
2018; Hoch et al., 2018). Ethical leadership has been identified as a valid distinct "leadership" construct rather than just another aspect of major leadership practices (e.g., transformational, transactional and authentic leadership) (Brown and Trevino, 2006; Walumbwa et al., 2011). In their seminal research, Brown and Trevino (2014) and Brown et al. (2005) defined ethical leaders as "considerate, trustworthy and morally upright individuals who make just decisions, candidly communicate acceptable ethical standards to their followers and become excellent role models by practicing these ethical standards themselve's. Ethical leadership incorporates two important dimensions. The first is the moral person dimension which overlaps with the ethical dimensions inherent to more traditional leadership styles (e.g., transformational leadership, authentic leadership). Moral persons possess personal traits and characteristics such as honesty, integrity and trustworthiness" (Brown and Trevino, 2006, 2014).

The second dimension is that of the moral manager who proactively seeks to influence follower's ethical conduct (Brown and Trevino, 2006). These proactive efforts encompass the communication of high-performance expectations and role modeling behaviors that are normatively appropriate and good for the collective using reinforcement systems to hold people responsible for appropriate conduct while treating people fairly and with respect (Brown and Mitchell, 2010). While other leadership styles, such as transformational and authentic leadership also capture leader's personal traits, what clearly sets ethical leadership apart from more traditional leadership styles is the hands-on approach that characterizes the moral manager dimension (Brown et al., 2005; Piccolo et al., 2010; Walumbwa et al., 2011, 2017). Consequently, the following hypothesis is proposed:

- $\mathrm{H}_{1}$ : ethical leadership has a positive effect on employee performance

Leader-Member Exchange (LMX) and employee performance: The role of leaders and their relationship with subordinates have long been considered critical for employee performance (Howell and Hall-Merenda, 1999; Janssen and Van Yperen, 2004; Wang et al., 2005; Erdogan and Enders, 2007; Restubog et al., 2010; Zhang et al., 2012; Walumbwa et al., 2017). LMX theory contends that leaders develop a different relationship with each of their subordinates through a series of work-related exchanges (Graen and Scandura, 1987). High-quality LMX relationships tend to be characterized by mutual respect, liking and trust (Dansereau et al., 1975). The quality of LMX reflects a specific form of 
social exchange within the organization (e.g., Cropanzano et al., 2002; Masterson et al., 2000; Restubog et al., 2010; Walumbwa et al., 2017). Social exchange theory posits that individuals give benefits to others in expectation of receiving benefits of equivalent value from them in return (Howell and Hall-Merenda, 1999; Martin et al., 2016). In addition, the norm of reciprocity suggests that people come to feel themselves under obligation and in turn want to help persons and organizations that have helped them (Sekiguchi et al., 2008; Audenaert et al., 2016; Martin et al., 2016).

Once, a certain quality LMX relationship has been formed, the relationship between the leader and the members of each group has distinct characteristics. Individuals with a high-quality LMX are provided with more authority to make decisions (Schriesheim et al., 1998; Yukl and Fu, 1999) are given special information to help them complete tasks (Schriesheim et al., 1998) are consulted prior to decisions (Yukl and Fu, 1999) and are given special mentoring opportunities (Graen and Scandura, 1987). Therefore, high-quality LMX will lead to greater motivation to perform their tasks well and engage in OCBs drawing on what discussed. Consequently, the following hypothesis is proposed:

- $\mathrm{H}_{2}$ : LMX influences positively on employee's performance

Affective Organizational Commitment (AOC) and employee performance: The effect of organizational commitment on employee performance and organizational effectiveness has prompted much interest among researchers (Allen and Meyer, 1996; Karim and Noor, 2017). Organizational commitment refers to an individual's overall feelings about the organization. It is the psychological bond that an employee has with an organization and has been found to be related to behavioral investments in the organization, likelihood to stay with the organization and goal and value congruence (Mowday et al., 1982; Ahmad et al., 2014; Lee and Steers, 2017; Mohamed et al., 2018). In this knowledge-based economy, it has become more important than ever in understanding individual work-related behavior because it is identified as more stable and less subject to daily fluctuations than job satisfaction (Mowday et al., 1982; Ahmad et al., 2014).

Organizational commitment is a measure of an employee's identification with his or her organization (Ahmad et al., 2014; Johnson, 2015; Karim and Noor, 2017). A meta-analysis on studies over the past 25 years across 14 countries (Jaramillo et al., 2005; Ahmad et al., 2016; Devece et al., 2016) indicated that the relationship between organizational commitment and job performance is positive and stronger for sales employees than for non-sales employees. Stronger correlations between organizational commitment and job performance were also found for collectivist compared to individualistic cultures. Ahmad et al. (2014) revealed a positive relationship between organizational commitment and employee's job performance and in the comparative analysis of three dimensions of organizational commitment, normative commitment has a positive and significant impact on employee's job performance. Darolia et al. (2010) in a survey of 231 male-skilled workers from different units of National Fertilizer Ltd., India, found a positive correlation between organizational commitment and organizational support and their significant contribution in determining job performance. Hence, it is hypothesized as follows:

- $\mathrm{H}_{3}$ : AOC influences positively on employee's performance

Employee Performance (PERF): The components of creativity, innovation, productivity, competitiveness, profitability, effectiveness and efficiency exist at all levels at which PERF may be defined that is whether organizational level, process level or staff/work unit level (Antony and Bhattacharyya, 2010; Khalifa and Fawzy, 2017; Mohamed et al., 2018). These measurements and constituents of PERF are not basically relevant to all business procedures and work unit measurement of PERF. Nonetheless, they represent covering indicators that can be considered as the yield of any activity performed inside the workplace. Results from studying the relationship between EL practices and employee performance have been mixed (Brown and Trevino, 2006, 2014; Yidong and Xinxin, 2013; Tang et al., 2015; Chen and Hou, 2016), consequently, there is a need remains to re-test this relationship. Repetition study contributes empirical generalizations and knowledge progress and reliable research findings amongst numerous studies using a diversity of methodologies give support to the strength and generality of research results (Kaynak, 2003). Replication research also contributes to authenticating cause-and-effect relations, uniting the empirical findings of a discipline and enhancing knowledge by decreasing type one errors by assessing the robustness and generalization of empirical finding and by developing theory through sustaining the criterion of reproducibility.

\section{MATERIALS AND METHODS}

Overview of the proposed research model: For this study, the hypothesized variables and their relationships in the 


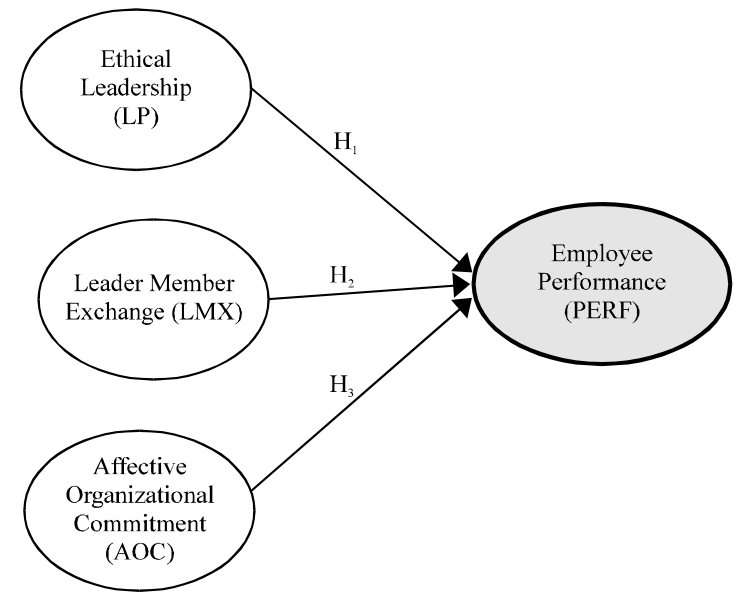

Fig. 1: Proposed research model

model have been derived from the available literature of the models and theories that have been prescribed in the literature mentioned above. The proposed model can be seen in Fig. 1. While, examining the proposed model, it can be seen that LMX and AOC along with EL predicts employees performance. These relationships are derived from Brown et al. (2005) and Brown and Trevino (2006) for EL, MacKenzie et al. (1991) and Podsakoff et al. (2003) for PERF, Allen and Meyer (1996) for AOC and Wayne et al. (1997) for LMX. The proposed extended model examines the relationship between EL, AOC and LMX as antecedent variables that explain employee performance as an output variable among employees in police institutions in the United Arab Emirates. The proposed model has three hypothesis to test.

Development of instrument: A 26-item questionnaire was developed for this study. Because the respondents were Arab-speaking, it was imperative that it be accurately translated from English to Arabic. Back translation was used in this study, a procedure commonly used in cross-cultural surveys to test the accuracy of the translation (Brislin, 1970).

This study applied multi-item Likert scales which have been widely used in the questionnaire-based perception studies (Lee et al., 2009). Unlike actual usage which is measured using a 7-point ranking scale, other variables are subjectively measured using the 7-point Likert scale with 7 being 'Strongly Agree' and 1 being 'Strongly Disagree'. For this study, a pre-testing was conducted with 25 policemen from UAE to resolve any ambiguity associated with wording or measurement. Then the items were pilot-tested to examine their internal consistency. Out of 660 surveys administered to UAE employees in the Ministry of Interior, 558 were returned with complete and valid data. In the final questionnaire, all items had acceptable reliability as the individual Cronbach's alpha coefficients of the constructs which ranged from $0.85-0.950$ were all greater than the recommended value of 0.7 (Nunnally, 1994).

Data collection: Data collection was conducted using a self-administered paper questionnaire which was delivered 'in-person' from April 2017 until August 2017 to police officers and their immediate supervisors. The employees were approached while in main facilities at police institutions. A total of 700 questionnaires were distributed with 578 sets returned of which 558 responses were useful for the analysis. The final sample size was considered as adequate (Krejcie and Morgan, 1970; Tabachnick and Fidell, 2012). The $79.7 \%$ response rate is considered very good (Cable and DeRue, 2002) and above average (Baruch and Holtom, 2008) by comparison with other studies found in the relevant literature. A total of 20 questionnaires were deleted of which 14 cases were removed due to missing data for more than $15 \%$ of the questions and 6 cases involving straight lining.

\section{RESULTS AND DISCUSSION}

Descriptive analysis: Demographic profile of respondents shows that $388(68.3 \%)$ were male and $180(31.7 \%)$ female. $13.9 \%$ were $<25$ years old, $41.2 \%$ between 25 and 30 , $36.3 \%$ between $31-35$ years, $8.6 \%$ between 36,40 and $3.7 \%$ being 50 years and above. In terms of education background, $88.4 \%$ had a bachelor degree (the majority of participants) with the remaining $9 \%$ having finished postgraduate studies. In terms of tenure, $9 \%$ were $<1$ year's experience, $34 \%$ between 1 and $5,39.8 \%$ between $6-10$ years, $13.6 \%$ between 11,15 and $3.6 \%$ being 15 years and above.

Measurement model assessment: This study employed Structural Equation Modeling-Variance Based (SEM-VB) through Partial Least Squares (PLS) method to analyze the research model using the software of SmartPLS 3.0 (Ringle and Sarstedt, 2016). After the descriptive analysis, this study follows the two-stage analytical technique recommended by Anderson and Gerbing (1988) and Hair et al. (2017), starts with the measurement model assessment (validity and reliability), followed by the structural model assessment (testing the hypothesized relationships). Schumacker and Lomax (2004) and Hair et al. (2010) indicate that the two steps assessment procedure which includes measurement model and structural model has an advantage over the one step assessment procedure. According to Hair et al. (2017) 
Table 1: Summary of demographic profile of respondents

\begin{tabular}{lcc}
\hline Variables & Frequency & Valid (\%) \\
\hline Gender & 388 & \\
Male & 180 & 68.3 \\
Female & & 31.7 \\
Age & 79 & \\
$<25$ & 234 & 13.9 \\
$25-30$ & 206 & 41.2 \\
$31-35$ & 49 & 36.3 \\
$36-40$ & & 08.6 \\
Education & 502 & \\
Bachelor & 66 & 88.4 \\
Post graduate & & 11.6 \\
Tenure & 51 & \\
$<1$ year & 193 & 09.0 \\
$1-5$ & 226 & 34.0 \\
6-10 & 77 & 39.8 \\
$11-15$ & 21 & 13.6 \\
More than 15 & & 03.6 \\
\hline
\end{tabular}

measurement model specifies how each construct is measured while structural model specifies how the variables are related to each other in the structural model. The main reasons for choosing PLS as a statistical method for this study that for both measurement and structural model PLS offer simultaneous analysis which leads to more accurate estimates (Barclay et al., 1995).

The assessment of measurement model was done through construct reliability as well as validity (including convergent and discriminant validity). For construct reliability, this study tested the individual Cronbach's alpha coefficients to measure the reliability of each of the core variables in the measurement model. The results indicate that all the individual Cronbach's alpha coefficients ranging from $0.85-0.95$ were higher than the suggested value of 0.7 (Kannana and Tan, 2005; Nunnally, 1994). Additionally, for testing construct reliability all the Composite Reliability (CR) values ranging from 0.85-0.95 were higher than 0.7 (Werts et al., 1974; Kline, 2010; Gefen et al., 2000) which adequately indicates that construct reliability is fulfilled as shown in Table 1. Therefore, the achieved Cronbach's alpha and CR for all constructs were considered to be sufficiently error-free.

Factor loading was used to test indicator reliability. High loadings on a construct indicate that the associated indicators seem to have much in common which is captured by the construct (Hair et al., 2017). Factor loadings $>0.50$ were considered to be very significant (Hair et al., 2010). The loadings for all items exceeded the recommended value of 0.5 as shown in Table 1 . The loading for all items in the model has therefore, fulfilled all the requirements.

For testing convergent validity (the extent to which a measure correlates positively with alternative measures of the same construct), this study used the Average Variance Extracted (AVE) and it indicated that all AVE
Table 2: Mean, standard deviation, loading, Cronbach's alpha, CR and

\begin{tabular}{|c|c|c|c|c|c|c|}
\hline Constructs/items & $\begin{array}{l}\text { Loading } \\
(>0.5)\end{array}$ & $\mathrm{M}$ & SD & $\begin{array}{l}\alpha \\
(>0.7)\end{array}$ & $\begin{array}{l}\text { CR } \\
(>0.7)\end{array}$ & $\begin{array}{l}\text { AVE } \\
(>0.5) \\
\end{array}$ \\
\hline \multicolumn{7}{|c|}{ Ethical Leadership (EL) } \\
\hline EL1 & 0.757 & 4.644 & 0.899 & 0.930 & 0.941 & 0.614 \\
\hline EL2 & 0.773 & & & & & \\
\hline EL3 & 0.837 & & & & & \\
\hline EL4 & 0.822 & & & & & \\
\hline EL5 & 0.825 & & & & & \\
\hline EL6 & 0.789 & & & & & \\
\hline EL7 7 & 0.759 & & & & & \\
\hline EL8 & 0.788 & & & & & \\
\hline EL9 & 0.750 & & & & & \\
\hline EL10 & 0.730 & & & & & \\
\hline \multicolumn{7}{|c|}{ Leader-Member Exchange (LMX) } \\
\hline LMX1 & 0.792 & 4.727 & 0.784 & 0.915 & 0.932 & 0.686 \\
\hline LMX2 & 0.842 & & & & & \\
\hline LMX3 & 0.865 & & & & & \\
\hline LMX4 & 0.839 & & & & & \\
\hline LMX5 & 0.777 & & & & & \\
\hline LMX 6 & 0.804 & & & & & \\
\hline LMX7 & 0.771 & & & & & \\
\hline \multicolumn{7}{|c|}{ Affective Organizational Commitment (AOC) } \\
\hline $\mathrm{AOC} 1$ & 0.801 & 4.560 & 1.015 & 0.909 & 0.929 & 0.662 \\
\hline $\mathrm{AOC} 2$ & 0.807 & & & & & \\
\hline $\mathrm{AOC} 3$ & 0.838 & & & & & \\
\hline AOC4 & 0.820 & & & & & \\
\hline AOC5 & 0.830 & & & & & \\
\hline AOC6 & 0.872 & & & & & \\
\hline \multicolumn{7}{|c|}{ Employee Per formance (EPF) } \\
\hline PERF1 & 0.872 & 4.736 & 1.042 & 0.897 & 0.928 & 0.763 \\
\hline PERF2 & 0.890 & & & & & \\
\hline PERF3 & 0.882 & & & & & \\
\hline PERF4 & 0.849 & & & & & \\
\hline
\end{tabular}

$\mathrm{M}=$ Mean, $\mathrm{SD}=$ Standard Deviation, $\alpha=$ Cronbach's alpha, $\mathrm{CR}=$ Composite Reliability, $\mathrm{AVE}=$ Average Variance Extracted, the measurement used is seven-point scale ranging from 1 (strongly disagree) to 7 (strongly agree), all the factor loadings of the individual items are statistically significant $(\mathrm{p}<0.01)$

values were higher than the suggested value of 0.50 (Hair et al., 2010) ranging from $0.540-0.683$. The convergent validity for all constructs has been successfully fulfilled and adequate convergent validity exhibited as Table 2 shows.

The discriminant validity (the degree to which items differentiate among constructs or measure distinct concepts) of the measurement model was checked using three criteria, namely cross-loadings, Fornell-Larcker and the HeteroTrait-MonoTrait ratio (HTMT). According to Hair et al. (2017), the cross-loadings are typically the first approach to assess discriminant validity of the indicators. As shown in Table 3 the cross loading criterion fulfills the requirements because the indicators outer loadings on a construct were higher than all its cross-loadings with other constructs (bold values).

The results of discriminant validity by using the Fornell-Larcker criterion is shown in Table 4 where the square root of the AVEs on the diagonals as represented by the bolded values are higher than the correlations between constructs (corresponding row and column 
Table 3: Results of discriminant validity by the cross loading

\begin{tabular}{|c|c|c|c|c|}
\hline Variables & $\mathrm{AOC}$ & $\mathrm{EL}$ & LMX & PERF \\
\hline AOC1 & 0.801 & 0.454 & 0.451 & 0.548 \\
\hline $\mathrm{AOC} 2$ & 0.807 & 0.463 & 0.499 & 0.580 \\
\hline AOC3 & 0.838 & 0.463 & 0.580 & 0.535 \\
\hline AOC4 & 0.820 & 0.470 & 0.586 & 0.548 \\
\hline AOC5 & 0.830 & 0.602 & 0.579 & 0.642 \\
\hline AOC6 & 0.872 & 0.579 & 0.608 & 0.630 \\
\hline EL1 & 0.464 & 0.757 & 0.472 & 0.577 \\
\hline EL2 & 0.458 & 0.773 & 0.515 & 0.495 \\
\hline EL3 & 0.505 & 0.837 & 0.632 & 0.627 \\
\hline $\mathrm{EL} A$ & 0.457 & 0.822 & 0.555 & 0.605 \\
\hline EL5 & 0.443 & 0.825 & 0.542 & 0.614 \\
\hline EL6 & 0.467 & 0.789 & 0.556 & 0.541 \\
\hline EL7 & 0.506 & 0.759 & 0.519 & 0.534 \\
\hline EL8 & 0.516 & 0.788 & 0.619 & 0.537 \\
\hline EL9 & 0.457 & 0.750 & 0.570 & 0.520 \\
\hline EL10 & 0.553 & 0.730 & 0.456 & 0.538 \\
\hline LMX1 & 0.533 & 0.514 & 0.792 & 0.537 \\
\hline LMX2 & 0.509 & 0.597 & 0.842 & 0.565 \\
\hline LMX3 & 0.576 & 0.619 & 0.865 & 0.610 \\
\hline LMX4 & 0.559 & 0.601 & 0.839 & 0.584 \\
\hline LMX5 & 0.579 & 0.505 & 0.777 & 0.535 \\
\hline LMX6 & 0.518 & 0.603 & 0.804 & 0.530 \\
\hline LMX7 & 0.518 & 0.500 & 0.771 & 0.488 \\
\hline PERF1 & 0.633 & 0.673 & 0.593 & 0.872 \\
\hline PERF2 & 0.596 & 0.622 & 0.597 & 0.890 \\
\hline PERF3 & 0.617 & 0.576 & 0.532 & 0.882 \\
\hline PERF4 & 0.611 & 0.624 & 0.640 & 0.849 \\
\hline
\end{tabular}

EL: Ethical Leadership, LMX: Leader-Member Exchange, PERF: Employee Performance, AOC: Affective Organizational Committment

Table 4: Results of discriminant validity by Fornell-Larcker criterion Values

\begin{tabular}{lllll} 
& & & 3 & 4 \\
\hline AOCtors & 1 & 2 & & \\
EL & 0.829 & & & \\
LMX_- & 0.614 & 0.784 & & \\
PERF & 0.666 & 0.694 & 0.814 & 0.874 \\
\hline
\end{tabular}

Diagonals represent the square root of the average variance extracted while the other entries represent the correlations; EL: Ethical Leadership, LMX: Leader-Member Exchange, PERF: Employee Performance, AOC: Affective Organizational Committment

values). This indicates that the constructs are strongly related to their respective indicators compared to other constructs of the model (Fornell and Larcker, 1981; Chin, 1998 a, b), thus, suggesting a good discriminant validity (Hair et al., 2017). In addition, the correlation between exogenous constructs is $<0.85$ (Awang, 2014). Hence, the discriminant validity of all constructs is fulfilled.

There has been some criticism of the Fornell and Larcker (1981) and Henseler et al. (2015) mentioned that it does not accurately reveal the lack of discriminant validity in common research situations. They have proposed an alternative technique which is the HeteroTrait-MonoTrait ratio (HTMT) of correlations based on the multitrait-multimethod matrix. This study assesses discriminant validity through HTMT. While, the discriminant validity has a problem when the HTMT value is greater than HTMT0.90 value of 0.90 (Gold et al., 2001) or the HTMT0.85 value of 0.85 (Kline, 2010), all values as Table 5 shows were lower than the recommended value of 0.85 indicating that discriminant validity has been ascertained.
Structural model assessment: Hair et al. (2017) suggested assessing the structural model by looking at the beta $(\beta), \mathrm{R}^{2}$ and the corresponding t-values via. a bootstrapping procedure with a resample of 5,000 . Moreover, they recommend reporting the effect sizes $\left(\mathrm{f}^{2}\right)$ as well as the predictive relevance $\left(\mathrm{Q}^{2}\right)$. As (Sullivan and Feinn, 2012) argue that the p-value determine whether the effect exists but it does not reveal the size of the effect.

Hypothesis tests: The structural model assessment as shown in Fig. 2 and Table 4 provides the indication of the hypothesis tests with 3 out of the 3 hypothesis are supported. EL, LMX and AOC significantly predict employee performance. Hence, $\mathrm{H}_{1}-\mathrm{H}_{3}$ are accepted with $(\beta=0.370, \tau=7.815, p<0.001),(\beta=0.186, \tau=3.467$, $\mathrm{p}<0.01)$ and $(\beta=0.353, \tau=6.386, \mathrm{p}<0.001)$, respectively.

Note that the standardized path coefficient indicates the strengths of the relationship between exogenous and endogenous constructs, so, the direct effects of EL on employee performance are much stronger than the influence of other variables.

EL, AOC and LMX explaining $63.9 \%$ of the variance in employee performance. The $\mathrm{R}^{2}$ values achieved an acceptable level of explanatory power as recommended by Cohen (1988) and Chin (1998a, b) indicating a substantial model.

This study also assessed effect sizes $\left(\mathrm{f}^{2}\right)$. Effect size $\mathrm{f}^{2}$ determines whether an exogenous latent construct has a substantial, moderate or weak impact on an endogenous latent construct (Gefen and Rigdon, 2011). Hair et al. (2017) recommend to test the change in the $\mathrm{R}^{2}$ value. Cohen (1988) suggested a guideline measure the magnitude of the $\mathrm{f}^{2}$ which is 0.35 (large effects), 0.15 (medium effects) and 0.02 (small effects). The result of $\mathrm{f}^{2}$ as Table 4 shows that two relationship with medium effect sizes and one relationships with small effect sizes.

Further by using the blindfolding procedure this study examined the power of research proposed model regarding the predictive relevance. As recommended by Hair et al. (2017) the blindfolding procedure should use only on the endogenous constructs with a reflective measurement. If the value of $Q^{2}>0$, then, the predictive relevance of the proposed model exists for a certain endogenous construct (Fornell and Cha, 1994; Hair et al., 2017). As Table 4 shows that all the values of $Q^{2}>0$ indicate that there is an adequate predictive relevance for the proposed model. For the $\mathrm{Q}^{2}$ values, Hair et al. (2017) suggested values of 0.35 (large), 0.15 (medium) and 0.02 (small) as a relative measure of predictive relevance and the result of this study shows that the exogenous have large predictive relevance. 


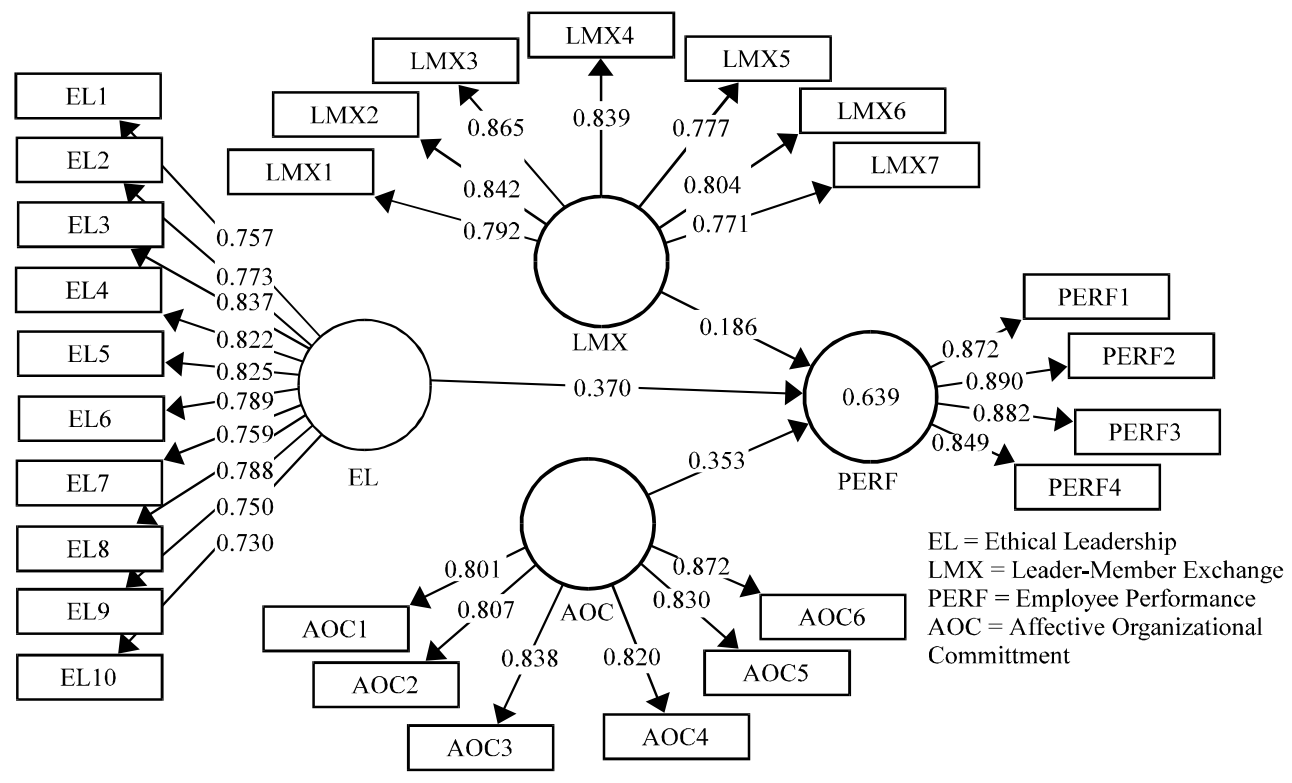

Fig. 2: PLS algorithm results

\begin{tabular}{lccc}
\multicolumn{2}{l}{ Table 5: Results of discriminant validity by HTMT } & & \\
\hline Factors & AOC (1) & EL (2) & LMX (3) \\
AOC & & & \\
EL & 0.665 & & \\
LMX & 0.730 & 0.751 & 0.745 \\
PERF & 0.776 & 0.779 & \\
\hline
\end{tabular}

Table 6: Structural path analysis result

\begin{tabular}{|c|c|c|c|c|c|c|c|c|c|}
\hline Hypothesis/relationship & $\operatorname{std} \beta$ & SE & t-values & $p$-values & Decision & $\mathrm{R}^{2}$ & $\mathrm{f}^{2}$ & $\mathrm{Q}^{2}$ & VIF \\
\hline $\mathrm{H}_{1}:$ EL->PERF & 0.370 & 0.047 & 7.815 & 0.000 & Supported & 0.639 & 0.181 & 0.456 & 1.810 \\
\hline $\mathrm{H}_{2}: \mathrm{LMX}->\mathrm{PERF}$ & 0.186 & 0.054 & 3.467 & 0.001 & Not-supported & & 0.041 & & 2.075 \\
\hline$\underline{\mathrm{H}_{3}}: \mathrm{AOC}->\mathrm{PERF}$ & 0.353 & 0.055 & 6.386 & 0.000 & Supported & & 0.176 & & 1.485 \\
\hline
\end{tabular}

EL: Ethical Leadership, LMX: Leader-Member Exchange, PERF: Employee Performance, AOC: Affective Organizational Committment

An issue of the multicollinearity could exist in any study which is not desirable, it means that the variance exogenous constructs explain in the endogenous construct are overlapping with each other and thus, not each explaining unique variance in the endogenous variable (O'Brien, 2007). To measure and assess the degree of multicollinearity, Variance Inflation Factor (VIF) widely used (O'Brien, 2007). There is cause for concern when the largest VIF is $>10$ (Bowerman and O'Connell, 1990; Myers, 1990). And according to Hair et al. (2017) a multicollinearity issue exists when the largest VIF is $>5$. Table 5 shows multicollinearity diagnostic through VIF which indicates that there is no evidence of significant multicollinearity among the study exogenous constructs because all VIF values are $>5$ ranging from 1.485-2.075. It means that the variance of exogenous constructs explains in the endogenous construct are not overlapping with each other Table 6.

Importance-Performance Map Analysis (IPMA): This study ran an Importance-Performance Matrix
Analysis (IPMA) as a post-hoc procedure in PLS using organizational performance as the outcome construct. The IPMA estimates the total effects represented by the importance of predecessor constructs in shaping the target construct (organizational performance) while their average latent variable scores represent their performance, the computation of the index values (performance scores) was accomplished by rescaling the latent constructs scores to a range of 100 (highest performance) down to 0 (lowest performance) (Hair et al., 2017). According to Ringle and Sarstedt (2016) IPMA enriches the PLS analysis results. Instead of only analyzing the path coefficients (i.e., the importance dimension), it also takes into consideration the average value of the latent constructs and their indicators (i.e., performance dimension). Table 7 shows the findings of importance (total effects) and performance (index values) used for the IPMA.

As shown in Fig. 3 this study plotted the total effects scores and index values in a priority map. It can be observed that EL is a very important factor in determining 
Table 7: IPMA for employee performance

\begin{tabular}{lll}
\hline Latent constructs & $\begin{array}{l}\text { Total effect of the } \\
\text { construct PERF } \\
\text { (importance) }\end{array}$ & $\begin{array}{l}\text { Index values } \\
\text { (performance) }\end{array}$ \\
\hline $\begin{array}{l}\text { Affective Organizational } \\
\text { Commitment (AOC) }\end{array}$ & 0.353 & 61.850 \\
$\begin{array}{l}\text { Ethical Leadership (EL) } \\
\text { Leader-Member Exchange (LMX) }\end{array}$ & 0.370 & 61.095 \\
\hline
\end{tabular}

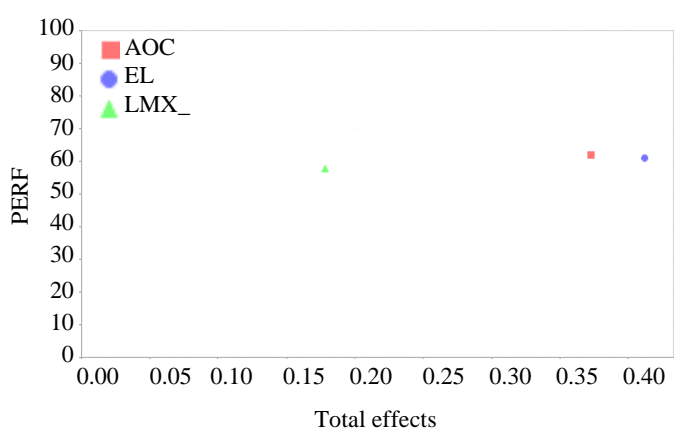

Fig. 3: IPMA (Priority Map) for employee performance

the employee performance due to its relatively higher importance value compared to other constructs in the proposed model.

Nevertheless, the performance of this significant factor (EL) lagged behind the AOC. According to Hair et al. (2017) the goal of IPMA is to identify predecessors that have a relatively high importance for the target construct (i.e., those that have a strong total effect) but also a relatively low performance (i.e., low average latent variable scores), the aspects underlying these constructs represent potential areas of improvement that may receive high attention. In sum, in order to improve the employee performance, the managerial activities should focus on enhancing the performance of EL.

Based on the proposed model, this study improves the understanding of the role played by AOC, LMX and $\mathrm{EL}$ in the employee performance at police institutions in the United Arab Emirates and highlights relevant implications and suggestions for management and policy makers. The discussions are further detailed in the following.

The study found that EL positively affect employee performance among policemen within the Abu Dhabi police in the United Arab Emirates, this is supported by previous studies (Walumbwa et al., 2011; Zehir and Erdogan, 2011; Bello, 2012; Sabir et al., 2012; Yidong and Xinxin, 2013; Bouckenooghe et al., 2015; Chen and Hou, 2016; Dhar, 2016). It is explained by the fact that the more the leadership of the organization is committed to establishing directions that will be aligned with all activities, teams and units that will ultimately be at the best interests of Abu Dhabi police service needs, besides encouraging cooperation, team work and social responsibility commitment, the more resource efficient the organization become and more likely to achieve optimal quality, besides meeting its benchmarks on time to perform its duties.

Likewise, it was found that AOC positively affect employee performance among workers within the Abu Dhabi police in the United Arab Emirates, this is supported by previous studies (Meyer et al., 1989; Allen and Meyer, 1996; Babakus et al., 2003; Ahmad et al., 2014; Fu and Deshpande, 2014; Atmojo, 2015; Lee and Steers, 2017). In this knowledge-based economy, it has become more important than ever in understanding individual work-related behavior because it is identified as more stable and less subject to daily fluctuations than job satisfaction (Joo, 2010). The more AOC the employees becomes and more likely to achieve optimal quality, besides meeting its benchmarks on time to perform their duties.

Additionally, LMX was found to positively affect employee performance among respondents within the Abu Dhabi police in the United Arab Emirates, this is supported by previous studies (Almatrooshi et al., 2016; Reb et al., 2018; Audenaert et al., 2016; Martin et al., 2016). It is explained by the fact that the more the high quality relationship between supervisors and their subordinates, the more to enhance their performance in the UAE security sector and more likely to achieve optimal quality, besides meeting their benchmarks on time to perform their duties.

Finally, according to the importance-performance map analysis, EL scored highest in terms of importance and AOC scored in terms of performance within the tested model. Therefore, in order for Abu Dhabi police to enhance its employee performance, leaders need to improve their ethical contribution in terms of moral person dimension and moral manager. Moreover, While other leadership styles such as transformational and authentic leadership, also capture leader's personal traits what clearly sets ethical leadership apart from more traditional leadership styles is the hands-on approach that characterizes the moral manager dimension (Brown et al., 2005; Piccolo et al., 2010; Walumbwa et al., 2011; Walumbwa et al., 2017).

\section{CONCLUSION}

While, the United Arab Emirates government institutions are ahead of regional counterparts in terms of performance, it is striving to enhance its public organization's productivity (Index, 2016), the findings of 
this study could be considered as one of the initiatives to serve on that direction. The main objective of this study is to determine factors that affect employee performance within Abu Dhabi police institutions in the United Arab Emirates. Despite various constraints to the study, the results have been encouraging as it has managed to throw some lights on a new perspective. This study proposed a model which includes EL and AOC, in addition to LMX as independent variables and employee performance as the dependent variable. The results revealed that the 3 independent variables significantly explain $64 \%$ of employee performance. The implications of this study from the perspective of research and practitioners have been deliberated, limitations have been noted and some directions for future research have been suggested.

\section{IMPLICATIONS}

Implications for research: This research paper has made use of the available literature of the concept of EL, AOC and LMX by applying it to the context of an organization in the public sector in the United Arab Emirates to examine its role as a source of competitive advantage and its effect on the employee performance. This research can be seen as an attempt to contribute to the understanding of the organizational performance that leads to a firm's enhanced productivity and thus enhanced competitive advantage (Rao, 2016). This concept has significant value for researchers interested in employee performance. Moreover, the variance explained by the proposed model in the current study for employee performance among knowledge workers within the police institutions in the United Arab Emirates is $63.9 \%$. The predictive power of the model in this study has therefore, a higher ability to explain and predict employee performance than obtained from some of the previous studies with different variances explained recorded for employee performance: $35.3 \%$ (Ahmad et al., 2014), 64.2\% (Atmojo, 2015). This research offers empirical support to the theoretical relevance of EL and $\mathrm{AOC}$, along with LMX to predict the performance of organizations.

Implication for practice: The present research is of significant for practitioners as it illustrates the importance of AOC, LMX and EL, although, a link of causality between the variables of this study cannot be clearly recognized because of the cross-sectional design, the results indicate that $\mathrm{EL}, \mathrm{AOC}$ and $\mathrm{LMX}$ are vital to facilitate and enhance the employee performance. The order of this sequence should encourage organizations to put more emphasis on nurturing leader's moral person dimension and moral manager one. Moreover, the implications of the key findings provide significant benefits not only for at police institutions but also to the UAE local government authorities. Incorporating the findings, a number of practical implications were found such as promoting leaders ethical behavior as well as AOC and LMX which leads to improving employee performance and quality of work.

It is expected that key findings, especially, the proposed model will help in supporting the UAE government policy initiatives, especially, to increase performance as part of the job at all levels of organizations. The evidence shows a link between AOC and better LMX and performance (Restubog et al., 2010; Atmojo, 2015; Ahmad et al., 2016; Dhar, 2016; Karim and Noor, 2017; Walumbwa et al., 2017).

\section{LIMITATIONS}

The first limitation concerns the generalizability of the findings; the targeted sampling of this study includes an employee working in police institutions in the United Arab Emirates only. Another limitation is that data was gathered by cross-sectional and is not longitudinal in nature. The relationships between variables prescribed in the model of this study are highly case-dependent and thus they vary from organization to another, the model was implemented for an example organization which is Abu Dhabi police.

\section{SUGGESTIONS}

As described in the introduction section of this research. Moreover, the exclusion of other organizational resources, for instance, financial resources represents another limitation of the model. Although, such resources are necessary for organizations in the successful implementation of their capability-building plans, it was decided that taking into account these organizational resources in the model will result in more unnecessary complications to the model and reduce from the main objectives of this research.

\section{REFERENCES}

Abd-Elaziz, M.E., W.M. Aziz, G.S. Khalifa and M. Abdel-Aleem, 2015. Determinants of Electronic Word of Mouth (EWOM) influence on hotel customers purchasing decision. Intl. J. Heritage Tourism Hospitality, 9: 194-223. 
Abou-Shouk, M.A. and G.S. Khalifa, 2017. The influence of website quality dimensions on E-purchasing behaviour and E-loyalty: A comparative study of Egyptian travel agents and hotels. J. Travel Tourism Marketing, 34: 608-623.

Ahmad, J., M.R. Athar and M. Hussain, 2016. Linking personality traits with job performance mediating role of organizational commitment: An empirical evidence. NUML. Intl. J. Bus. Manage., 11: 1-11.

Ahmad, N., N. Iqbal, K. Javed and N. Hamad, 2014. Impact of organizational commitment and employee performance on the employee satisfaction. Intl. J. Learn. Teach. Educ. Res., 1: 84-92.

Allen, N.J. and J.P. Meyer, 1996. Affective, continuance and normative commitment to the organization: An examination of construct validity. J. Vocational Behav., 49: 252-276.

Almatrooshi, B., S.K. Singh and S. Farouk, 2016. Determinants of organizational performance: A proposed framework. Intl. J. Productivity Perform. Manage., 65: 844-859.

Anderson, J.C. and D.W. Gerbing, 1988. Structural equation modeling in practice: $\mathrm{A}$ review and recommended two-step approach. Psychol. Bull., 103: 411-423.

Antony, J.P. and S. Bhattacharyya, 2010. Measuring organizational performance and organizational excellence of SMEs-Part 1: A conceptual framework. Measuring Bus. Excellence, 14: 3-11.

Atmojo, M., 2015. The influence of transformational leadership on job satisfaction, organizational commitment and employee performance. Int. Res. J. Bus. Stud., 5: 113-128.

Audenaert, M., A. Decramer, B. George, B. Verschuer and T. Van Waeyenberg, 2016. When employee performance management affects individual innovation in public organizations: The role of consistency and LMX. Intl. J. Hum. Resour. Manage., 1: 1-20.

Awang, Z., 2014. Structural Equation Modeling Using AMOS. Universiti Teknologi MARA, Shah Alam, Malaysia,

Ayers, R.S., 2015. Aligning individual and organizational performance: Goal alignment in federal government agency performance appraisal programs. Publ. Personnel Manage., 44: 169-191.

Babakus, E., U. Yavas, O.M. Karatepe and T. Avci, 2003. The effect of management commitment to service quality on employees' affective and performance outcomes. J. Acad. Marketing Sci., 31: 272-286.

Badran, N. and G. Khalifa, 2016. Diversity management: Is it an important issue in hotel industry in Egypt?. Intl. J. Heritage Tourism Hospitality, 7: 275-286.
Barclay, D., C. Higgins and R. Thompson, 1995. The Partial Least Squares (PLS) approach to causal modeling: Personal computer adoption and use as an illustration. Technol. Stud., 2: 285-309.

Baruch, Y. and B.C. Holtom, 2008. Survey response rate levels and trends in organizational research. Hum. Relat., 61: 1139-1160.

Bauer, T.N. and S.G. Green, 1996. Development of leader-member exchange: A longitudinal test. Acad. Manage. J., 39: 1538-1567.

Bello, S.M., 2012. Impact of ethical leadership on employee job performance. Int. J. Bus. Soc. Sci., 3: 228-236.

Belschak, F.D., D.N. Den Hartog and A.H. De Hoogh, 2018. Angels and demons: The effect of ethical leadership on machiavellian employees work behaviors. Front. Psychol., 9: 1-36.

Bouckenooghe, D., A. Zafar and U. Raja, 2015. How ethical leadership shapes employees job performance: The mediating roles of goal congruence and psychological capital. J. Bus. Ethics, 129: 251-264.

Bowerman, B.L. and R.T. O'Connell, 1990. Linear Statistical Models: An Applied Approach. 2nd Edn., Duxbury Press, Grove, California, USA., ISBN:9780534229856, Pages: 1024.

Brislin, R.W., 1970. Back-translation for cross-cultural research. J. Cross Cult. Psychol., 1: 185-216.

Brown, M.E. and L.K. Trevino, 2006. Ethical leadership: A review and future directions. Leadership Q., 17: 595-616.

Brown, M.E. and L.K. Trevino, 2014. Do role models matter? An investigation of role modeling as an antecedent of perceived ethical leadership. J. Bus. Ethics, 122: 587-598.

Brown, M.E. and M.S. Mitchell, 2010. Ethical and unethical leadership. Bus. Ethics Q., 20: 583-616.

Brown, M.E., L.K. Trevino and D.A. Harrison, 2005. Ethical leadership: A social learning perspective for construct development and testing. Org. Behav. Hum. Decis. Process., 97: 117-134.

Buch, R., G. Thompson and B. Kuvaas, 2016. Transactional leader-member exchange relationships and followers work performance: The moderating role of leaders political skill. J. Leadersh. Organizational Stud., 23: 456-466.

Byun, G., S.J. Karau, Y. Dai and S. Lee, 2018. A three-level examination of the cascading effects of ethical leadership on employee outcomes: A moderated mediation analysis. J. Bus. Res., 88: 44-53.

Cable, D.M. and D.S. DeRue, 2002. The convergent and discriminant validity of subjective fit perceptions. J. Applied Psychol., 87: 875-884. 
Carter, M.Z., A.A. Armenakis, H.S. Feild and K.W. Mossholder, 2013. Transformational leadership, relationship quality and employee performance during continuous incremental organizational change. J. Organizational Behav., 34 : 942-958.

Chen, A.S.Y. and Y.H. Hou, 2016. The effects of ethical leadership, voice behavior and climates for innovation on creativity: A moderated mediation examination. Leadersh. Q., 27: 1-13.

Chen, X.P., M.B. Eberly, T.J. Chiang, J.L. Farh and B.S. Cheng, 2014. Affective trust in Chinese leaders linking paternalistic leadership to employee performance. J. Manage., 40: 796-819.

Chin, W.W., 1998a. Commentary: Issues and opinion on structural equation modeling. MIS Q., 22: 7-16.

Chin, W.W., 1998b. The partial least squares approach to structural equation modeling. Modern Methods Bus. Res., 295: 295-336.

Cohen, J., 1988. Statistical Power. 2nd Edn., Lawrence Erlbaum Associates, New Jersey, USA., ISBN: 9780805802832 , Pages: 567.

Colquitt, J.A., B.A. Scott and J.A. LePine, 2007. Trust, trustworthiness and trust propensity: A meta-analytic test of their unique relationships with risk taking and job performance. J. Appl. Psychol., 92: 909-927.

Colquitt, J.A., D.E. Conlon, M.J. Wesson, C.O. Porter and K.Y. Ng, 2001. Justice at the millennium: A meta-analytic review of 25 years of organizational justice research. J. Applied Psychol., 86: 425-445.

Cropanzano, R., C.A. Prehar and P.Y. Chen, 2002. Using social exchange theory to distinguish procedural from interactional justice. Group Organiz. Manage., 27: 324-351.

Dansereau Jr, F., G. Graen and W.J. Haga, 1975. A vertical dyad linkage approach to leadership in formal organizations. Organ. Behav. Human Perform., 13: 46-78.

Darolia, C.R., P. Kumari and S. Darolia, 2010. Perceived organizational support, work motivation and organizational commitment as determinants of job performance. J. Indian Acad. Appl. Psychol., 36: 69-78.

Demirtas, O. and A.A. Akdogan, 2015. The effect of ethical leadership behavior on ethical climate, turnover intention and affective commitment. J. Bus. Ethics, 130: 59-67.

Devece, C., D. Palacios-Marques and M.P. Alguacil, 2016. Organizational commitment and its effects on organizational citizenship behavior in a high-unemployment environment. J. Bus. Res., 69: 1857-1861.
Dhar, R.L., 2016. Ethical leadership and its impact on service innovative behavior: The role of LMX and job autonomy. Tourism Manage., 57: 139-148.

Dienesch, R.M. and R.C. Liden, 1986. Leader-member exchange model of leadership: A critique and further development. Acad. Manage. Rev., 1: 618-634.

Dulebohn, J.H., W.H. Bommer, R.C. Liden, R.L. Brouer and G.R. Ferris, 2012. A meta-analysis of antecedents and consequences of leader-member exchange: Integrating the past with an eye toward the future. J. Manage., 38: 1715-1759.

Eisenberg, N., 2014. Altruistic Emotion, Cognition and Behavior (PLE: Emotion). Psychology Press, Hove, UK., ISBN:9781317597421, Pages: 255.

Eisenberger, R., M.K. Shoss, G. Karagonlar, M.G. Gonzalez-Morales and R.E. Wickham et al., 2014. The supervisor POS-LMX-subordinate POS chain: Moderation by reciprocation wariness and supervisors organizational embodiment. J. Organizational Behav., 35: 635-656.

Epitropaki, O., I. Kapoutsis, B.P. Ellen III, G.R. Ferris and $\mathrm{K}$. Drivas et al., 2016. Navigating uneven terrain: The roles of political skill and LMX differentiation in prediction of work relationship quality and work outcomes. J. Organizational Behav., 37: 1078-1103.

Erdogan, B. and J. Enders, 2007. Support from the top: Supervisors perceived organizational support as a moderator of leader-member exchange to satisfaction and performance relationships. J. Appl. Psychol., 92: $321-330$.

Erdogan, B., R.C. Liden and M.L. Kramer, 2006. Justice and leader-member exchange: The moderating role of organizational culture. Acad. Manage. J., 49: 395-406.

Fiaz, M., Q. Su and A. Saqib, 2017. Leadership styles and employees motivation: Perspective from an emerging economy. J. Dev. Areas, 51: 143-156.

Fornell, C. and D.F. Larcker, 1981. Evaluating structural equation models with unobservable variables and measurement error. J. Market. Res., 18: 39-50.

Fornell, C. and J. Cha, 1994. Partial Least Squares. In: Advanced Methods in Marketing Research, Bagozzi, R.P. (Ed.). Blackwell,? Oxford?, England, UK., pp: 52-78.

Fu, W. and S.P. Deshpande, 2014. The impact of caring climate, job satisfaction and organizational commitment on job performance of employees in a Chinas insurance company. J. Bus. Ethics, 124: 339-349.

Gefen, D. and E.E. Rigdon, 2011. An update and extension to SEM guidelines for administrative and social science research. MIS. Q., 35: 1-7. 
Gefen, D., D.W. Straub and M.C. Boudreau, 2000. Structural equation modeling and regression: Guidelines for research practice. Commun. Assoc. Inform. Syst., 4: 1-77.

Gold, A.H., A. Malhotra and A.H. Segars, 2001. Knowledge management: An organizational capabilities perspective. J. Manage. Inform. Syst., 18 : 185-214.

Graen, E.B. and T.A. Scandura, 1987. Toward a psychology of dyadic organizing. Res. Org. Behav., 9: 174-208.

Graen, G.B. and M. Uhl-Bien, 1995. Relationship-based approach to leadership: Development of Leader-Member Exchange (LMX) theory of leadership over 25 years: Applying a multi-level multi-domain perspective. Leadersh. Q., 6: 219-247.

Greenberg, J., 1996. The Quest for Justice on the Job: Essays and Experiments. Sage Publications, Thousand Oaks, CA., ISBN: 9780803959675 , Pages: 428.

Hair, Jr. J.F., W.C. Black, B.J. Babin and R.E. Anderson, 2010. Multivariate Data Analysis. 7th Edn., Prentice-Hall, Upper Saddle River, NJ., USA., ISBN-13: 978-0138132637, Pages: 816.

Hair, Jr., J.F., G.T.M. Hult, C.M. Ringle and M. Sarstedt, 2017. A Primer on Partial Least Squares Structural Equation Modeling (PLS-SEM). 2nd Edn., Sage Publisher, Thousand Oaks, California.

Henseler, J., C.M. Ringle and M. Sarstedt, 2015. A new criterion for assessing discriminant validity in variance-based structural equation modeling. J. Acad. Marketing Sci., 43: 115-135.

Hoch, J.E., W.H. Bommer, J.H. Dulebohn and D. Wu, 2018. Do ethical, authentic and servant leadership explain variance above and beyond transformational leadership? A meta-analysis. J. Manage., 44: 501-529.

Howell, J.M. and K.E. Hall-Merenda, 1999. The ties that bind: The impact of leader-member exchange, transformational and transactional leadership and distance on predicting follower performance. J. Applied Psychol., 84: 680-694.

Hsiung, H.H. and M.C. Bolino, 2018. The implications of perceived leader favouritism in the context of leader-member exchange relationships. Eur. J. Work Organizational Psychol., 27: 88-99.

Hussein, I.E., M.A. Abou-Shouk and G.S. Khalifa, 2013. Evaluating tourism and hospitality graduates: Perceptions of stakeholders in Egypt. Proceedings of the 3rd Regional Conference on Tourism Research, October 29-31, 2013, Bayview Hotel, Langkawi, Malaysia, pp: 764-774.
Index, G.I., 2016. Government institutions effectiveness: Yemen versus Arab countries: Rank among 143 countries. World Intellectual Property Organization (WIPO), Cornell University, Ithaca, New York, USA.

Janssen, O. and N.W. Van Yperen, 2004. Employees goal orientations, the quality of leader-member exchange and the outcomes of job performance and job satisfaction. Acad. Manage. J., 47: 368-384.

Jaramillo, F., J.P. Mulki and G.W. Marshal, 2005. A meta-analysis of the relationship between organizational commitment and salesperson job performance: 25 years of research. J. Bus. Res., 586 : 705-714.

Johnson, R.R., 2015. Police organizational commitment: The influence of supervisor feedback and support. Crime Delinquency, 61: 1155-1180.

Joo, B.K., 2010. Organizational commitment for knowledge workers: The roles of perceived organizational learning culture, leader-member exchange quality and turnover intention. Hum. Resour. Dev. Q., 21: 69-85.

Kannan, V.R. and K.C. Tan, 2005. Just in time, total quality management and supply chain management: Understanding their linkages and impact on business performance. Omega, 33: 153-162.

Karim, N.H.A. and N.H.N.M. Noor, 2017. Evaluating the psychometric properties of Allen and Meyers organizational commitment scale: A cross cultural application among Malaysian academic librarians. Malaysian J. Library Inf. Sci., 11: 89-101.

Kaynak, H., 2003. The relationship between total quality management practices and their effects on firm performance. J. Oper. Manage., 21: 405-435.

Khalefa, G.S.A., 2015. Ethnic restaurants meal experience: Egyptian customers perceptions. Intl. J. Heritage Tourism Hospitality, 9: 92-112.

Khalifa, G.S. and E.H.M. Ali, 2017. Managing drivers and boundaries of Information Technology Risk Management (ITRM) to increase Egyptian hotels market share. Intl. J. Recent Trends Bus. Tourism, 1: 12-31.

Khalifa, G.S. and M.A. Abou-Shouk, 2014. Investigating the success factors of hotel websites: The case of Egyptian hotels. Asia Pac. J. Innovation Hospitality Tourism, 3: 131-151.

Khalifa, G.S.A. and M. Hewedi, 2016. Factors affecting hotel website purchasing intentions: Evidence from Egypt. J. Faculty Tourism Hotels, Fayoum Univ., 8: $50-69$. 
Khalifa, G.S.A. and N. Fawzy, 2017. Measuring E-service quality (Expectation vs Perception) from travel agencies perspective an empirical study on Egyptian hotel websites. Intl. J. Recent Trends Bus. Tour., 1: 36-48.

Kim, B.G., S.C. Park and K.J. Lee, 2008. A structural equation modeling of the internet acceptance in Korea. Electron. Commerce Res. Appl., 6: 425-432.

Kline, R.B., 2010. Principles and Practice of Structural Equation Modeling. 3rd Edn., The Guilford Press, New York, USA., ISBN-13: 9781606238769 , Pages: 427.

Krejcie, R.V. and D.W. Morgan, 1970. Determining sample size for research activities. Educ. Psychol. Meas., 30: 607-610.

Lee, B.C., J.O. Yoon and I. Lee, 2009. Learner's acceptance of e-learning in South Korea: Theories and results. Comput. Educ., 53: 1320-1329.

Lee, T.W. and R.M. Steers, 2017. Facilitating Effective Performance Appraisals: The Role of Employee Commitment and Organizational Climate. In: Performance Measurement and Theory, Landy, F., S. Zedeck and J. Cleveland (Eds.). Routledge, Abingdon, UK., pp: 75-93.

Liao, C., S.J. Wayne, R.C. Liden and J.D. Meuser, 2017. Idiosyncratic deals and individual effectiveness: The moderating role of leader-member exchange differentiation. Leadersh. Q., 28: 438-450.

Loi, R., Y. Mao and H.Y. Ngo, 2009. Linking leader-member exchange and employee work outcomes: The mediating role of organizational social and economic exchange. Manage. Organ. Rev., 5: 401-422.

Lozano, R., K. Ceulemans, M. Alonso-Almeida, D. Huisingh and F.J. Lozano et al., 2015. A review of commitment and implementation of sustainable development in higher education: Results from a worldwide survey. J. Cleaner Prod., 108: 1-18.

MacKenzie, S.B., P.M. Podsakoff and R. Fetter, 1991. Organizational citizenship behavior and objective productivity as determinants of managerial evaluations of salespersons' performance. Organiz. Behav. Hum. Decis. Process, 50: 123-150.

Martin, R., Y. Guillaume, G. Thomas, A. Lee and $O$. Epitropaki, 2016. Leader-member exchange (LMX) and performance: A meta-analytic review. Personnel Psychol., 69: 67-121.

Masterson, S.S., K. Lewis, B.M. Goldman and M.S. Taylor, 2000. Integrating justice and social exchange: The differing effects of fair procedures and treatment on work relationships. Acad. Manage. J., 43: 738-748.
Meyer, J.P., V. Paunon, I.R. Gellatly, R.D. Goffin and D.N. Jackson, 1989. Organizational commitment and job performance. J. Applied Psychol., 74: 152-156.

Mohamed, M.S., G.S. Khalifa, M. Nusari, A. Ameen and A.H. Al-Shibami et al., 2018. Effect of organizational excellence and employee performance on organizational productivity within healthcare sector in the UAE. J. Eng. Appl. Sci., 13: 6199-6210.

Mohamud, S.S., G.S.A. Khalifa, A.E. Abuelhassan and S. Kaliyamoorthy, 2017. Investigating the antecedents of coffee shop customers' behavioral intentions in Kuala Lumpur. Intl. J. Recent Trends Bus. Tourism, 1: 1-14.

Mowday, R.T., L.W. Porter and R.M. Steers, 1982. Employee-Organizational Linkages: The Psychology of Commitment, Absenteeism and Turnover. In: Organizational and Occupational Psychology, Warr, P. (Ed.). Academic Press, Cambridge, Massachusetts, USA., pp: 219-229.

Myers, R.H., 1990. Classical and Modern Regression with Applications. 2nd Edn., Duxbury/Thompson Learning, Boston, USA., ISBN-13: 9780534380168 , Pages: 488 .

Niu, C.P., A.C. Wang and B.S. Cheng, 2009. Effectiveness of a moral and benevolent leader: Probing the interactions of the dimensions of paternalistic leadership. Asian J. Soc. Psychol., 12: 32-39.

Nunnally, J.C., 1994. Psychometric Theory. 3rd Edn., McGraw-Hill Education, New York, USA., ISBN:9780071070881, Pages: 752.

Nusari, M., M. Al Falasi, I. Alrajawy, G.S. Khalifa and $O$. Isaac, 2018. The impact of project management assets and organizational culture on employee performance. Intl. J. Manage. Hum. Sci., 2: 15-26.

O'Brien, R.M., 2007. A caution regarding rules of thumb for variance inflation factors. Qual. Quantity, 41: 673-690.

Park, S., M.C. Sturman, C. Vanderpool and E. Chan, 2015. Only time will tell: The changing relationships between LMX, job performance and justice. J. Appl. Psychol., 100: 660-680.

Piccolo, R.F., R. Greenbaum, D.N.D. Hartog and R. Folger, 2010. The relationship between ethical leadership and core job characteristics. J. Organizational Behav., 31: 259-278.

Pillai, R., T.A. Scandura and E.A. Williams, 1999. Leadership and organizational justice: Similarities and differences across cultures. J. Int. Bus. Stud., 30: 763-779. 
Podsakoff, P.M., S.B. MacKenzie, J.Y. Lee and N.P. Podsakoff, 2003. Common method biases in behavioral research: A critical review of the literature and recommended remedies. J. Applied Psychol., 88: 879-903.

Qoura, O. and G.S.A. Khalifa, 2016. The impact of reputation management on hotel image among internal customers: The case of egyptian hotels. Intl. J. Heritage Tourism Hospitality, 7: 261-274.

Rao, M.S., 2016. Collaborate to build effective teams to achieve organizational excellence and effectiveness. Ind. Commer. Training, 48: 24-28.

Reb, J., S. Chaturvedi, J. Narayanan and R.S. Kudesia, 2018. Leader mindfulness and employee performance: A sequential mediation model of LMX quality, interpersonal justice and employee stress. J. Bus. Ethics, 1: 1-19.

Restubog, S.L.D., P. Bordia, R.L. Tang and S.A. Krebs, 2010. Investigating the moderating effects of leader-member exchange in the psychological contract breach-employee performance relationship: A test of two competing perspectives. Br. J. Manage., 21: 422-437.

Ringle, C.M. and M. Sarstedt, 2016. Gain more insight from your PLS-SEM results: The importance-performance map analysis. Ind. Manage. Data Syst., 116: 1865-1886.

Sabir, M.S., J.J. Iqbal, K.U. Rehman, K.A. Shah and M. Yameen, 2012. Impact of corporate ethical vaulues on ethical leadership and employee performance. Int. J. Bus. Soc. Sci., 3: 163-171.

Scandura, T.A., 1999. Rethinking leader-member exchange: An organizational justice perspective. Leadersh. Q., 10: 25-40.

Schriesheim, C.A., L.L. Neider and T.A. Scandura, 1998. Delegation and leader-member exchange: Main effects, moderators and measurement issues. Acad. Manage. J., 41: 298-318.

Schumacker, R.E. and R.G. Lomax, 2004. A Beginner's Guide to Structural Equation Modeling. 2nd Edn., Lawrence Erlbaum, New York, USA.

Sekiguchi, T., J.P. Burton and C.J. Sablynski, 2008. The role of job embeddedness on employee performance: The interactive effects with leader-member exchange and organization-based self-esteem. Personnel Psychol., 61: 761-792.

Shamsi, R.S.H.A., A.A. Ameen, O. Isaac, A.H. Al-Shibami and G.S. Khalifa, 2018. The impact of innovation and smart government on happiness: Proposing conceptual framework. Intl. J. Manage. Hum. Sci., 2: $10-26$.
Shapiro, J.P. and J.A. Stefkovich, 2016. Ethical Leadership and Decision Making in Education: Applying Theoretical Perspectives to Complex Dilemmas. 4th Edn., Routledge, Abingdon, UK., ISBN: 9781317681106, Pages: 266.

Shin, Y., S.Y. Sung, J.N. Choi and M.S. Kim, 2015. Top management ethical leadership and firm performance: Mediating role of ethical and procedural justice climate. J. Bus. Ethics, 129: 43-57.

Sullivan, G.M. and R. Feinn, 2012. Using effect size-or why the $\mathrm{P}$ value is not enough. J. Graduate Med. Educ., 4: 279-282.

Tabachnick, B.G. and L.S. Fidell, 2012. Using Multivariate Statistics. 6th Edn., Pearson Education, Boston, MA., ISBN-13: 9780205849574 , Pages: 983.

Tang, P.M., Y.L. Bavik, Y. Chen and D. Tjosvold, 2015. Linking ethical leadership to knowledge sharing and knowledge hiding: The mediating role of psychological engagement. Intl. Proc. Econ. Dev. Res., 84: 71-76.

Ullah, I., R.M. Hameed and A.R. Kashif, 2017. Ethical leadership impacts intellectual capital facets paving way to foster innovative performance: A Pakistani software houses perspective. J. Managerial Sci., 11: 231-262.

Walumbwa, F.O., C.A. Hartnell and E. Misati, 2017. Does ethical leadership enhance group learning behavior? Examining the mediating influence of group ethical conduct, justice climate and peer justice. J. Bus. Res., 72: 14-23.

Walumbwa, F.O., D.M. Mayer, P. Wang, H. Wang and $\mathrm{K}$. Workman et al., 2011. Linking ethical leadership to employee performance: The roles of leader-member exchange, self-efficacy and organizational identification. Organizational Behav. Hum. Decis. Processes, 115: 204-213.

Wang, H., K.S. Law, R.D. Hackett, D. Wang and Z.X. Chen, 2005. Leader-member exchange as a mediator of the relationship between transformational leadership and followers' performance and organizational citizenship behavior. Acad. Manage. J., 48: 420-432.

Wayne, S.J., L.M. Shore and R.C. Liden, 1997. Perceived organizational support and leader-member exchange: A social exchange perspective. Acad. Manage. J., 40: 82-111.

Werts, C.E., R.L. Linn and K.G. Joreskog, 1974. Intraclass reliability estimates: Testing structural assumptions. Educ. Psychol. Meas., 34: 25-33. 
Yidong, T. and L. Xinxin, 2013. How ethical leadership influence employees' innovative work behaviour: A perspective of intrinsic motivation. J. Bus. Ethics, 116: 441-455.

Yukl, G. and P.P. Fu, 1999. Determinants of delegation and consultation by managers. J. Organiz. Behav. Intl. J. Ind. Occup. Organ. Psychol. Behav., 20: 219-232.
Zehir, C. and E. Erdogan, 2011. The association between organizational silence and ethical leadership through employee performance. Procedia Soc. Behav. Sci., 24: 1389-1404.

Zhang, Z., M.O. Wang and J. Shi, 2012. Leader-follower congruence in proactive personality and work outcomes: The mediating role of leader-member exchange. Acad. Manage. J., 55: 111-130. 